\title{
Design of Android Application for Telemedicine System to Improve Public Health Services
}

\author{
Sumiati $^{1,1}$, Haris Triono Sigit ${ }^{1}$, \\ ${ }^{1}$ Informatic Department, Universitas Serang Raya, Banten, Indonesia
}

\begin{abstract}
One of the services provided by health facilities in Indonesia is the heart condition's examination using Electrocardiogram machine. This service is important to provide because heart disease is one of the 10 most common causes of death in Indonesia. The electrocardiogram machine produces a print out that contains a graph of patient's heart condition status. A cardiologist reads an ECG Scan to diagnose whether the patient's heart condition is normal or abnormal. Health facilities that has a cardiologist is a secondary health facility located in the city but in the primary health facility in the village, although the examination by electrocardiogram machine can be done, the patient still have to wait for the diagnosis result because the print out result is sent first to the secondary health facility which has a cardiologist. Therefore it is necessary to design an Android Application for supporting telemedicine system as an effort to accelerate diagnostic service so that patient in primary health facility can also get immediate medical treatment.
\end{abstract}

\section{Introduction}

The rapid development of information technology has influenced various aspects of life. One of them in terms of health services for the community. The existing health facilities seek to improve the quality of services by utilizing information technology to process various types of medical information to assist medical procedures. The existence of health facilities such as government hospitals and private hospitals and community health centers is needed by the community to overcome various health problems.

Health problems that need to be addressed at this time is the disease that can cause the highest mortality rate. One of them is coronary heart disease where this disease in Indonesia mostly occur in age group which is 65-74 years old (3,6\%), 75 years up (3.2\%), 55-64 years $(2,1 \%)$ and $35-44$ years $(1.3 \%)$. Coronary heart disease is the leading cause of death in Indonesia [1].

People who lives in the city can check the condition of heart health in health facilities that belong to the category of secondary healthcare facilities ie hospitals and villagers can check the condition of heart health in health facilities that belong to the category of primary health care facilities namely Puskesmas. In primary health facilities, patients who have been examined for cardiovascular health with ECG scan machines should wait for the diagnosis of ECG scans by a cardiologist present in secondary health facilities. Efforts to improve health services in Puskesmas can be done with a technological innovation that is able to accelerate the delivery of medical information from Puskesmas to a cardiologist in

\footnotetext{
${ }^{1}$ Corresponding author: sumiati82@yahoo.com
} 
the hospital.

Innovation that needs to be done is to build applications that follow the concept of telemedicine systems. With this application, the quality of health services become better because people who lives in villages will still get optimal medical care from cardiologists. Applications built in addition to running on computer devices also need to be attempted to run on mobile devices because today mostly people in Indonesia use smartphone devices in their daily activities.

\section{Telemedicine System}

According to Fong [2], the term telemedicine comes from a simple description of the word 'tele' which means distant or distant from the Greek language, so telemedicine means medical services provided remotely. The term telemedicine refers to the utilization of telecommunication technology for medical diagnosis, treatment, and patient care[3].

Telemedicine and e-health are two areas of biomedical engineering, which are also multidisciplinary, but telemedicine is actually a subset of e-health. Telemedicine can be interpreted as the use of information and communication technology (including electronics, tele-communications, computers, informatics) to transfer (send and / or receive) medical information, to improve clinical services (diagnosis and therapy) and education [4].

Rapid technological developments are a factor supporting the development of telemedicine systems in Indonesia. Indonesia which is an archipelagic country can utilize this telemedicine system as an effort to improve the quality of public health service. The Benefits of Telemedicine include [5]:
a. Improved access to patients
b. Reduce patient costs
c. Reduce remoteness of physician needs
d. Improve the quality of health services.

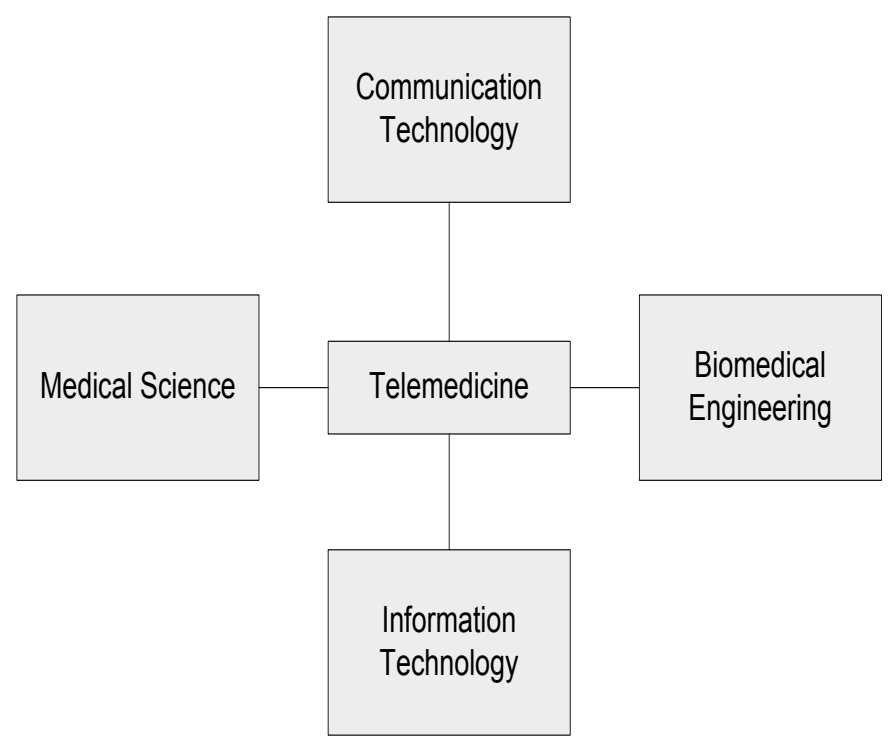

Fig 1. Telemedicine

Along with the pace of development of hardware and software technology as a device supporting telemedicine system has encouraged the development of telemedicine system significantly. One application is the application of telemedicine systems for monitoring and 
diagnosing patients using wireless technology. The main components of the system as illustrated below:
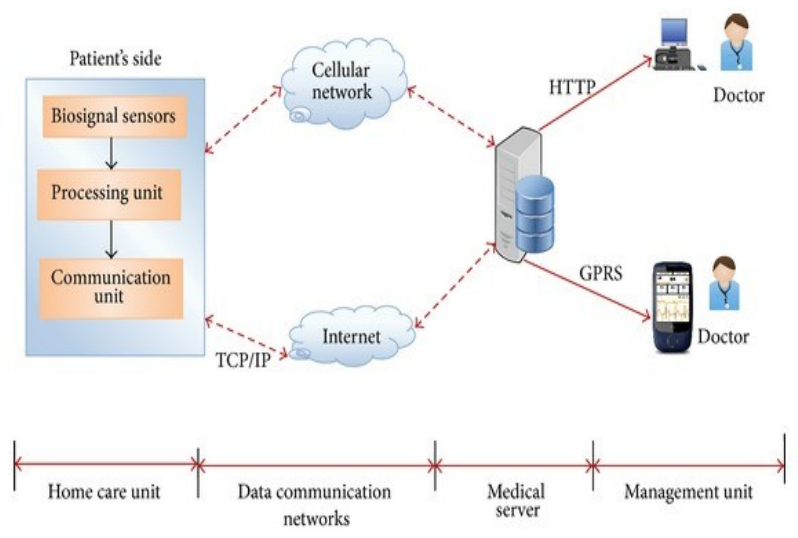

Fig 2. Main Components of Wireless Telemedicine System [6]

Based on the picture above, we can explain the flow of telemedicine system as follows:

a. The patient checks the health condition of the home using a Biosignal Sensor device

b. Further data checks the device is transmitted through a data communication network that can be a cellular network or internet network

c. Through the existing data communication network, data is transmitted to the server for processing and storage

d. Data stored in the server can be accessed by the doctor through the PC in the hospital or through the Smartphone.

In the development of telemedicine this should be noted about the issues that must be considered include: 1) The real effectiveness of the system, 2) Acceptability system, 3) System sustainability, and 4) Further development [7].

\section{Android Operating System}

The development of Smartphone technology is currently undergoing rapid development. In running the daily activities, humans can not be separated from the use of smartphone devices. This device is operated with an operating system for mobile devices such as iOS, Android, Blackberry, Windows Phone and others. The operating system that is commonly used is the Android operating system.

Android is a Mobile Operating System that grows in the middle of other OS that grows today [8]. The operating system is Linux-based and is for mobile devices. Android provides an open platform for developers to create their own applications for use by a variety of mobile devices. Android is commonly used in smartphones and tablet PCs and it has the same functionality as the Symbian operating system on Nokia, iOS on Apple and BlackBerry OS [9].

Android operating system has attracted the attention of the world community where companies gadgets and mobile phones are competing to create a device that runs under this operating system. The rapid development of the Android operating system seen from the versions that have been launched are as follows : 
Table 1. Version of Android Operating System [10]

\begin{tabular}{|l|l|l|}
\hline Name & Version & Launched \\
\hline Cupcake & 1.5 & April 27, 2009 \\
\hline Donut & 1.6 & September 15, 2009 \\
\hline Eclair & $2.0-2.1$ & October 26, 2009 \\
\hline Froyo & $2.2-2.2 .3$ & May 20, 2010 \\
\hline Gingerbread & $2.3-2.3 .7$ & December 6, 2010 \\
\hline Honeycomb & $3.0-3.2 .6$ & Februari 22, 2011 \\
\hline Ice Cream Sandwich & $4.0-4.0 .4$ & October 18, 2011 \\
\hline Jelly Bean & $4.1-4.3 .1$ & July 9, 2012 \\
\hline KitKat & $4.4-4.4 .4$ & October 31, 2013 \\
\hline Lollipop & $5.0-5.1 .1$ & November 12, 2014 \\
\hline Marshmallow & $6.0-6.0 .1$ & October 5, 2015 \\
\hline Nougat & 7.0 & August / September 2016 \\
\hline Oreo & 8.0 & August 2017 \\
\hline
\end{tabular}

The following diagram shows the major components of the Android platform [11]:

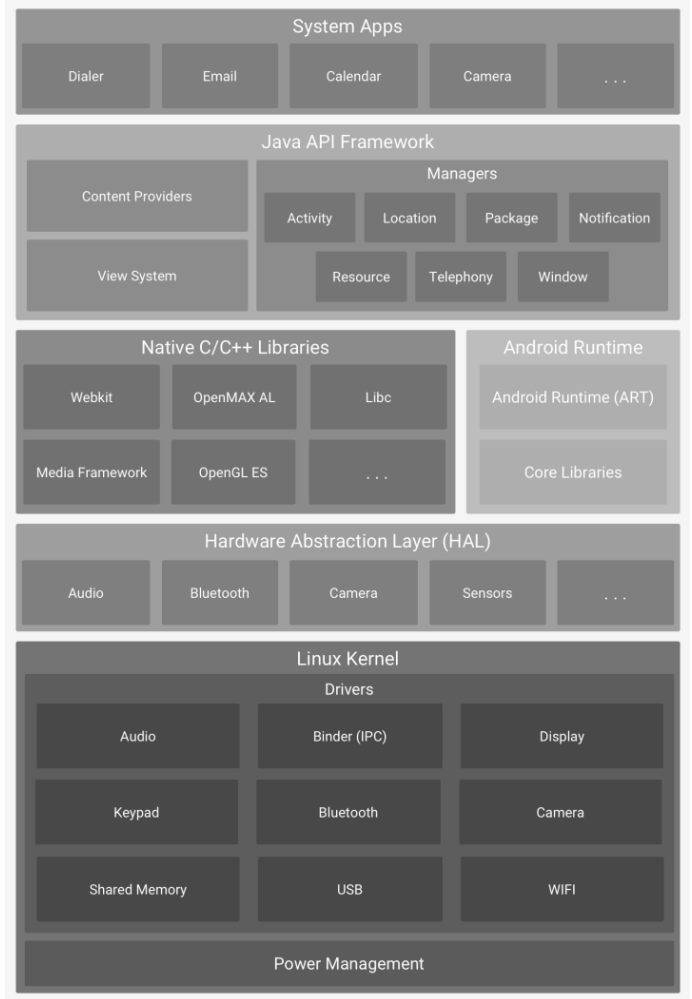

Fig 3. The Android software stack

The major components of the Android platform consists of:

a. Linux Kernel : The foundation of the Android platform is the Linux kernel. Using a Linux kernel allows Android to take advantage of key security features and allows device manufacturers to develop hardware drivers for a well-known kernel.

b. Hardware Abstraction Layer (HAL) : provides standard interfaces that expose device 
hardware capabilities to the higher-level Java API framework. The HAL consists of multiple library modules, each of which implements an interface for a specific type of hardware component, such as the camera or bluetooth module. When a framework API makes a call to access device hardware, the Android system loads the library module for that hardware component.

c. Android Runtime (ART) : is written to run multiple virtual machines on low-memory devices by executing DEX files, a bytecode format designed specially for Android that's optimized for minimal memory footprint. Build toolchains, such as Jack, compile Java sources into DEX bytecode, which can run on the Android platform.

d. Native $\mathrm{C} / \mathrm{C}++$ Libraries : Many core Android system components and services, such as $\mathrm{ART}$ and HAL, are built from native code that require native libraries written in $\mathrm{C}$ and $\mathrm{C}++$. The Android platform provides Java framework APIs to expose the functionality of some of these native libraries to apps.

e. Java API Framework: The entire feature-set of the Android OS is available to you through APIs written in the Java language. These APIs form the building blocks you need to create Android apps by simplifying the reuse of core, modular system components and services.

System Apps : Android comes with a set of core apps for email, SMS messaging, calendars, internet browsing, contacts, and more. Apps included with the platform have no special status among the apps the user chooses to install. So a third-party app can become the user's default web browser, SMS messenger, or even the default keyboard (some exceptions apply, such as the system's Settings app).

\section{The Design of Mobile Application for Telemedicine System}

Telemedicine systems can be developed in accordance with the support of emerging technologies today. The use of Android-based smartphones in almost all levels of society provides a great opportunity for the development of telemedicine systems to be applied to mobile devices.sIn this research, telemedicine system mobile application design to be built is as shown in table below:

Table 2. Use Case Definition of Telemedicine System

\begin{tabular}{|c|l|l|}
\hline No & \multicolumn{1}{|c|}{ Use case } & \multicolumn{1}{c|}{ Description } \\
\hline 1. & Register & $\begin{array}{l}\text { Patient requests } \\
\text { registration on the } \\
\text { system }\end{array}$ \\
\hline 2. & $\begin{array}{l}\text { Checking Heart } \\
\text { Condition }\end{array}$ & $\begin{array}{l}\text { Pasient do Checking the } \\
\text { heart condition }\end{array}$ \\
\hline 3. & Consult the doctor & $\begin{array}{l}\text { Patient conducts } \\
\text { cardiovascular } \\
\text { consultation with a } \\
\text { specialist }\end{array}$ \\
\hline 4. & $\begin{array}{l}\text { Monitoring Patient's } \\
\text { Condition }\end{array}$ & $\begin{array}{l}\text { The doctor monitors the } \\
\text { patient's condition and } \\
\text { provides medical } \\
\text { services when needed }\end{array}$ \\
\hline 5. & $\begin{array}{l}\text { Read Patient's Medical } \\
\text { Record }\end{array}$ & $\begin{array}{l}\text { Doctors read the } \\
\text { patient's medical } \\
\text { history to analyze the }\end{array}$ \\
\hline
\end{tabular}




\begin{tabular}{|c|l|l|}
\hline & & $\begin{array}{l}\text { patient's heart health } \\
\text { condition }\end{array}$ \\
\hline 6. & Login & $\begin{array}{l}\text { Doctor and Patient } \\
\text { enter the user name and } \\
\text { password }\end{array}$ \\
\hline
\end{tabular}

Based on the above table, the design of mobile application for telemedicine system can be described as follows:

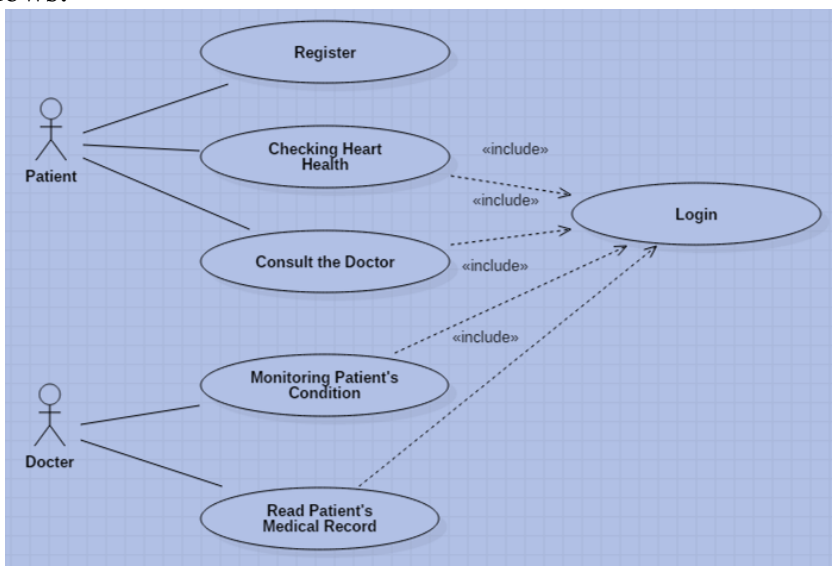

Fig 4. Use Case Diagram of Telemedicine Mobile Apps

\section{Conclusion}

Telemedicine systems can be further developed with the support of both hardware and software technology. The existence of a telemedicine system can solve health care problems in patients away from health facilities. Patients do not need to come to the hospital regularly to check their physical condition. With this telemedicine system, patients suffering from heart problems can check their heart health condition directly. Thus the physical condition and medical history of the patient can be monitored at any time by a team of cardiologist so that the team can immediately provide medical services.

With the support of mobile operating system technology allows telemedicine system can be applied to Smartphone device. The application of mobile-based telemedicine systems enables health services to be performed by doctors even when they are not in the hospital. With the optimal telemedicine system, medical information processing becomes faster so that efforts to improve the quality of health services to the community can be achieved.

\section{References}

1. Indonesian Ministry of Health, Heart Disease The Highest Cause of Death. [Online] Available in : http://www.depkes.go.id/article/view/17073100005/penyakit-jantung-penyebabkematian-tertinggi-kemenkes-ingatkan-cerdik-.html [Accessed date : May $^{13}$ 2018]

2. Fong, B., Fong, A.C.M, Li, C.K. 2011.Telemedicine Technologies : Information Technologies in Medicine and Telehealth (1st edition). United Kingdom: John Willey \& Sons.

3. J. C. Lin, “Applying telecommunication technology to health-care delivery," IEEE Eng. Med. Biol. Mag., vol. 18, pp. 28-31, 1999 
4. Soegijoko, S. 2010. Perkembangan Terkini Telemedika dan E-Health serta Prospek Aplikasinya di Indonesia. National Seminar on Information Technology Applications 2010 (SNATI2010), ISSN: 1907-5022

5. Satyamurthy LS, ISRO,s Experience in Telemedicine with Special Reference to Telemedicine System, 2007

6. M. Abo-Zahhad, SabahM. Ahmed, and O. Elnahas, A Wireless Emergency Telemedicine System for Patients Monitoring and Diagnosis. International Journal of Telemedicine and Applications, 2014

7. Kuat Indartono, Sistem Telemedika Berbasis ICT untuk Manajemen Fasilitas Unit Gawat Darurat. Journal of Electrical Engineering Vol. 5 No. 1, 2013

8. Hermawan S, Stephanus. 2011. "Mudah Membuat Aplikasi Android”.Yogyakarta : Andi Offset

9. H, Nazruddin Safaat. 2012. Pemrograman Aplikasi Mobile Smartphone dan Tablet PC Berbasis Android Edisi Revisi. Bandung: Informatika

10. https://haiwiki.info/aplikasi/tingkatan-versi-android [Accessed date : May ${ }^{14} 2018$ ]

11. https://developer.android.com/guide/platform [Accessed date : May ${ }^{14} 2018$ ]. 